Original Article

\title{
Effectiveness of awareness programme on prevention and management of diaper dermatitis among mothers of children of age 0 to 1 year
}

\author{
Maya K.S. ${ }^{1}$, Pai S.M. ${ }^{2}$ \& Anjalin D'Souza ${ }^{3}$ \\ ${ }^{1}$ M. Sc Student, ${ }^{2}$ Professor \& HOD, ${ }^{3}$ Assistant Professor, Department of Child Health Nursing, \\ Manipal College of Nursing, Manipal University, Karnataka, India.
}

Correspondence

Anjalin D'Souza

Assistant Professor, Department of Child Health Nursing, Manipal College of Nursing, Manipal University, Karnataka, India. E-mail : anjeline.d@manipal.edu

\begin{abstract}
The prevalence of diaper dermatitis in India is 4-35\% in the first 2 years of life. The incidence triples in babies with diarrhoea. A pre experimental study was conducted among the mothers of infants to determine the effectiveness of awareness programme on prevention and management of diaper dermatitis. The study was conducted in Kasturba Hospital, Manipal, Karnataka, India, among 42 mothers of children of age 0 to 1 year. The samples were selected through purposive sampling. Initially the level of knowledge, attitude and practice on prevention and management of diaper dermatitis were assessed by administering a structured questionnaire to mothers. Awareness programmes was given on the second day and on $8^{\text {th }}$ day a posttest was carried out and a significant improvement in knowledge $(t=13.813, p=0.02)$, attitude $(t=8.34, p=0.01)$ and practice $(t=11.32, p=0.01)$ were identified. The study findings showed that the awareness programme was effective in increasing the knowledge, attitude and practice on prevention and management of diaper dermatitis among the mothers of infants.
\end{abstract}

Keywords: Diaper dermatitis, awareness programme, knowledge

\section{Introduction}

The infants are unique when compared with older children and adults which make them highly susceptible to severe dermatological disorders. Diaper dermatitis can develop as early as one week of age, but it is found that the peak incidence occurs between the age of 9 and 12 months. For an infant the main person who cares is usually the mother. She is one who keeps the baby's skin stay healthy by preventing soreness. Great care has to be taken to establish a routine to maintain baby's skin healthy and hygienic whether at home or in health centre setting. ${ }^{2}$ Diaper dermatitis is a general definition used to describe a range

\begin{tabular}{|c|}
\hline Access this article online \\
\hline Quick Response Code \\
\hline
\end{tabular}

of inflammatory skin reactions in the diapering area. It is a common health problem and is estimated to affect up to $1 / 3^{\text {rd }}$ of nappy wearing infants. It equally affects boys and girls of all racial groups. ${ }^{1}$
A clinical study was conducted by Hodhod M A and Handy A $M$ on 63 infants with perianal dermatitis of more than 3 weeks with history of recurrence of diaper dermatitis. As per the researcher one main possible cause for diaper dermatitis was cow's milk allergy.The study results showed that the main causes of perianal dermatitis included cow's milk allergy (47.6\%), bacterial dermatitis (17.46\%), moniliasis (15.87\%), enterobiasis (9.52\%) and lactose intolerance $(9.5 \%){ }^{2}$

A survey was conducted by Scheinfeld N in the year 2005 on Diaper Dermatitis. The most important factors in the development of primary diaper dermatitis were found as moisture, urine, feces, friction and microorganisms. The possible treatments stated by the investigator were minimizing diaper use and using disposable diapers, mild topical cortisones, barrier creams and antifungal agents. ${ }^{3}$ An RCT was done in 2010 by Lavender T and Furber C on the effect of using baby wipes to clean the napkin area of newborn babies on skin hydration. The result of the 
study showed that baby wipes had an equal effect on skin hydration when cotton wool and water was compared with. The researcher found no evidence of any adverse effects of using baby wipes. ${ }^{4}$

The objectives of the present study was to find the effectiveness of awareness programme on knowledge, practice and attitude on prevention and management of diaper dermatitis among mothers of children of age 0 to 1 year.

\section{Materials and methods}

Pre experimental one group pre-test post test research design was used. Forty-two mothers of children of age 0 to 1 year admitted in the Kasturba Hospital, Manipal were selected through purposive sampling.

A demographic proforma with ten items was used to collect basic data related to mother and a clinical proforma with eleven items was used to collect data related to infant. A knowledge questionnaire was used which had 28 items under different areas like meaning, causes, risk factors, way of occurrence signs and symptoms, prevention, management and alternatives to diaper. According to the scores obtained the mothers were categorized into having poor knowledge with scores between 0-7, average knowledge with scores between 8-14, good knowledge with scores between 15-21 and excellent knowledge with scores between 22-28.

Attitude scale consisted of 25 items and scoring was given from 0 to 4 , scores were categorized as unfavorable attitude (0-50) and favorable attitude (51-100).Structured three point likert scale with 15 items was prepared to assess the practice and scores were categorized as poor practice (0-15) and good practice (16-30).

The tools on demographic proforma, clinical proforma and knowledge questionnaire and awareness program were validated by eight experts. The reliability of knowledge questionnaire was done by split half method and the reliability coefficient obtained was $r=0.9$.

After obtaining the ethical approval from the institutional ethical committee Kasturba Hospital Manipal, data were collected. The subject information sheet and informed consent were given to the mothers. On day 1 the demographic proforma, clinical proforma, structured knowledge questionnaire were administered. On day 2 an intervention was given in the form of an awareness programme of one hour duration, which included the concepts on meaning, causes, ways of occurrence, risk factor, signs \& symptoms, prevention, management and alternatives to diapers. In order to make the teaching effective, different methods like lecture, discussion and use of visual aids including flip charts and flash cards were incorporated during the teaching. On day 8 knowledge questionnaire attitude and practice sclae was administered for the posttest.

Descriptive statistics including frequency and percentage; and inferential statistics including mean, median, standard deviation, paired t test and spearmans rank correlation were used. ' $p$ ' value of 0.05 or less was considered significant.

\section{Results}

\section{Sample characteristics}

The data was analyzed based on the objectives and hypothesis of the study using descriptive and inferential statistics.

Table 1 : Sample characteristics of mothers of children of age 0 to 1 year.

$\mathrm{N}=42$

\begin{tabular}{llcc}
\hline $\begin{array}{l}\text { SI. } \\
\text { No }\end{array}$ & Sample characteristics & $\begin{array}{c}\text { Frequency } \\
\text { (f) }\end{array}$ & $\begin{array}{c}\text { Percentage } \\
\text { (\%) }\end{array}$ \\
\hline 1. & Age of mother (in years) & & \\
& $21-25$ & 12 & 28.6 \\
& $26-30$ & 23 & 54.8 \\
& $31-35$ & 5 & 11.9 \\
& $36-40$ & 2 & 4.8 \\
2 & Number of children & & \\
& 1 & 30 & 71.4 \\
& 2 & 12 & 28.6 \\
$3 \quad$ Type of family & & \\
& Nuclear & 16 & 38.1 \\
& Joint & 26 & 61.9 \\
Religion & & \\
& Hindu & 36 & 85.7 \\
& Christian & 2 & 4.8 \\
& Muslim & 4 & 9.5
\end{tabular}




\begin{tabular}{llcc}
\hline $\begin{array}{l}\text { Sl. } \\
\text { No }\end{array}$ & Sample characteristics & $\begin{array}{c}\text { Frequency } \\
\text { (f) }\end{array}$ & $\begin{array}{c}\text { Percentage } \\
\text { (\%) }\end{array}$ \\
\hline 5 & Educational status & & \\
& Primary & 3 & 7.1 \\
& Higher primary (class 6 and 7) & 6 & 14.3 \\
& High school (class 8-10) & 13 & 31 \\
High Secondary (class 11-12) & 7 & 16.7 \\
Diploma & 4 & 9.5 \\
Graduate & 8 & 19 \\
& Post graduate & 1 & 2.4 \\
Occupation & & \\
Employed & 3 & 7.1 \\
Homemaker & 39 & 92.9 \\
Monthly income (in rupees) & & \\
<3000 & 10 & 23.8 \\
3001-6000 & 17 & 40.5 \\
6001-9000 & 8 & 19 \\
& $>9001$ & 7 & 16.7
\end{tabular}

8 Previous experience of caring children with diaper dermatitis

$\begin{array}{lcc}\text { Yes } & 9 & 21.4 \\ \text { No } & 33 & 78.6\end{array}$

9 Any information regarding prevention \& management of diaper dermatitis

$\begin{array}{lll}\text { Yes } & 20 & 47.6 \\ \text { No } & 22 & 52.4\end{array}$

10 Source of health related information regarding prevention \& management of diaper dermatitis Family members $\quad 4 \quad 9.5$ $\begin{array}{lll}\text { Relatives } & 1 & 2.4\end{array}$

Health professionals $\quad 14 \quad 33.3$

$\begin{array}{lll}\text { Media } & 7 & 16.7\end{array}$

$\begin{array}{lll}\text { Others } & 7 & 16.7\end{array}$

$\begin{array}{lll}\text { Nil } & 8 & 19\end{array}$

It was found that most of the mothers $23(54.8 \%)$ belonged to the age group 26 to 30 years. Most of the mothers 13 (31\%) had educational qualification of high school. Some of the mothers 9 (21.4\%) had previous experience of caring babies with diaper dermatitis. A few mothers 20 (47.6\%) received information regarding prevention \& management of children with diaper dermatitis mainly from health professionals (33.3\%)

Table 2 : Sample characteristics of children of age 0 to 1 year.

$\mathrm{N}=42$

\begin{tabular}{llcc}
\hline $\begin{array}{l}\text { SI. } \\
\text { No }\end{array}$ & Sample characteristics & $\begin{array}{c}\text { Frequency } \\
\text { (f) }\end{array}$ & $\begin{array}{c}\text { Percentage } \\
\text { (\%) }\end{array}$ \\
\hline 1 & Age of child (in months) & & \\
& $0-4$ & 16 & 38.1 \\
& $5-8$ & 16 & 38.1 \\
& $9-12$ & 10 & 23.8 \\
2 & Sex of child & & \\
& Male & 17 & 59.5 \\
& Female & 25 & 40.5 \\
\hline
\end{tabular}

\begin{tabular}{|c|c|c|c|}
\hline $\begin{array}{l}\text { SI. } \\
\text { No }\end{array}$ & Sample characteristics & $\begin{array}{l}\text { Frequency } \\
\text { (f) }\end{array}$ & $\begin{array}{c}\text { Percentage } \\
\text { (\%) }\end{array}$ \\
\hline \multirow[t]{2}{*}{3} & \multicolumn{3}{|l|}{ Use of diapers for the child } \\
\hline & Yes & 31 & 73.8 \\
\hline & No & 11 & 26.2 \\
\hline \multicolumn{4}{|c|}{ PRACTICES } \\
\hline \multirow[t]{3}{*}{4} & \multicolumn{3}{|c|}{ Use of plastic underpants for the child } \\
\hline & Yes & 1 & 2.4 \\
\hline & No & 41 & 97.6 \\
\hline \multirow[t]{4}{*}{5} & Breastfeeding & & \\
\hline & Exclusive & 16 & 38.1 \\
\hline & Demand & 7 & 16.7 \\
\hline & Along with supplementary feed & 19 & 45.2 \\
\hline \multirow[t]{3}{*}{6} & Feeding with Cow's milk & & \\
\hline & Yes & 19 & 45.2 \\
\hline & No & 23 & 54.8 \\
\hline \multicolumn{4}{|c|}{ CLINICAL CHARACTERISTICS } \\
\hline \multirow[t]{3}{*}{7} & \multicolumn{3}{|c|}{$\begin{array}{l}\text { Child having soreness, redness or tenderness on the } \\
\text { diapering area }\end{array}$} \\
\hline & Yes & 8 & 19 \\
\hline & No & 34 & 81 \\
\hline \multirow[t]{3}{*}{8} & \multicolumn{3}{|c|}{ Child having any underlying disease } \\
\hline & Yes & 3 & 7.1 \\
\hline & No & 39 & 92.9 \\
\hline \multirow[t]{3}{*}{9} & \multicolumn{3}{|c|}{ Infant having risk factors for candidal infection } \\
\hline & Recent diarrhoea & 4 & 9.5 \\
\hline & Never & 38 & 90.5 \\
\hline \multirow[t]{3}{*}{10} & \multicolumn{3}{|c|}{ Previous diagnosis of diaper dermatitis } \\
\hline & Yes & 2 & 4.8 \\
\hline & No & 40 & 95.2 \\
\hline \multirow[t]{3}{*}{11} & Child receiving antibiotics & & \\
\hline & Yes & 13 & 31 \\
\hline & No & 29 & 69 \\
\hline
\end{tabular}

The sample characteristics of the infants showed that most of the infants 31 (73.8\%) diapers were used which included both cloth as well as commercial diapers. Among the infants, plastic underpant was used only for one infant. Some of the infants 8 (19\%) had soreness, redness or tenderness on the diapering area. Three infants $(7.1 \%)$ had previous illness. Four infants $(9.5 \%)$ had recent diarrhoea as risk factor for candidal infection. Two of them (4.8\%) were previously diagnosed with diaper dermatitis. Some of the infants 13 (31\%) were receiving antibiotics.

\section{Description of knowledge scores}

The area wise score on knowledge showed that the highest posttest percentage score was in the area of alternatives to diaper $(96.4 \%)$ and risk factors (88\%) followed by signs and symptoms (86.3\%). 
Fig. 1 : Bar graph showing area wise gain in the knowledge

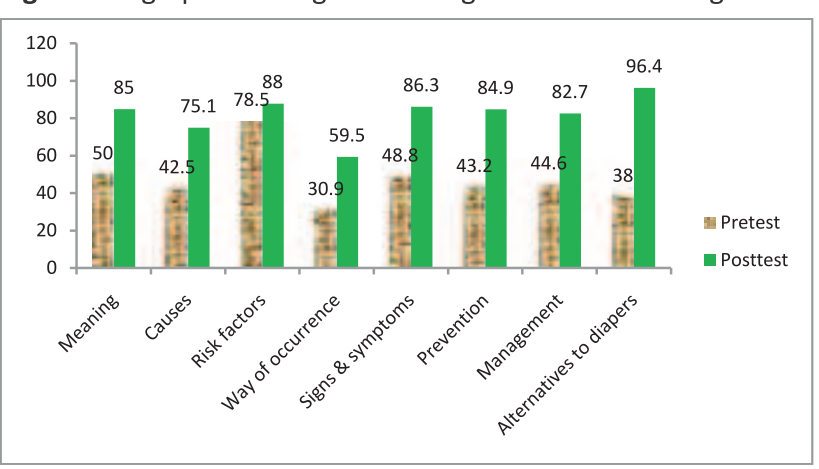

Fig. 2 : Line diagram showing frequency and percentage distribution of pretest and posttest knowledge scores of mothers.

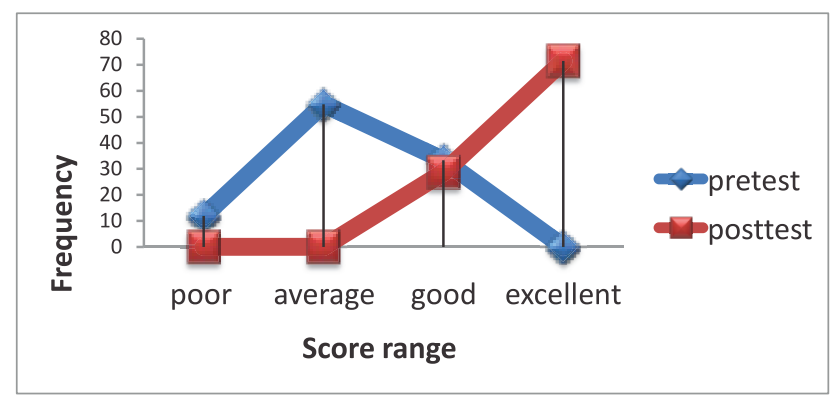

The pretest knowledge score showed that majority of the mothers 23(54.8\%) had average knowledge \& none of them had excellent knowledge. Whereas in post test maximum number of mothers 30 (71.4\%) had excellent knowledge \& none of them had average or poor knowledge.

Table 4 : The $t$ value computed between the mean pretest and posttest knowledge scores of mothers.

$\mathrm{N}=42$

\begin{tabular}{lcccc}
\hline & Mean & SD & $\boldsymbol{t}$ & $\mathbf{p}$ value \\
\hline Pretest & 12.67 & 4.437 & 13.813 & $0.022^{*}$ \\
Posttest & 22.62 & 3.702 & & \\
\hline$*$ p $<0.05$ & Maximum possible & & &
\end{tabular}

$* p<0.05$, Maximum possible score $=28$

Table 4 shows that there was a significant increase in the posttest mean score (22.62) of knowledge when compared to the pretest score (12.67). The $\boldsymbol{t}$ value computed (13.813) showed that it was significant at0.05 level. Hence the awareness programme was found to be effective in improving the knowledge of mothers.

Table 5 : The $t$ value computed between the mean pretest and posttest attitude scores of mothers.

$\mathrm{N}=42$

\begin{tabular}{lcccc}
\hline & Mean & SD & $\boldsymbol{t}$ & p value \\
\hline Pretest & 61.6 & 8.273 & 8.34 & $0.01^{*}$ \\
Posttest & 82.6 & 12.672 & & \\
\hline$*$ p $<0.05$, & Maximum possible score $=100$ & &
\end{tabular}

Table 5 shows that there was a significant increase in the posttest mean score (82.6) of attitude when compared to the pretest score (61.6). The $\boldsymbol{t}$ value computed (8.34) showed that it was significant at 0.01 level. Hence the awareness programme was found to be effective in improving the attitude of mothers.

Table 6 : The $t$ value computed between the mean pretest and posttest practice scores of mothers. $\mathrm{N}=42$

\begin{tabular}{llccc}
\hline & Mean & SD & $\boldsymbol{t}$ & $\mathbf{p}$ value \\
\hline Pretest & 18.64 & 3.184 & 11.324 & $0.01^{*}$ \\
Posttest & 25.64 & 3.477 & & \\
\hline${ }^{*} \mathrm{p}<0.05$, maximum score $=30$ & & &
\end{tabular}

Table 6 shows that there was a significant increase in the posttest mean score (18.64) of practice when compared to the pretest score (25.64). The $\boldsymbol{t}$ value computed (11.324) showed that it was significant at0.01 level. Hence the awareness programme was found to be effective in improving the practice of mothers.

\section{Discussion}

The present study revealed that out of the 42 samples, $54.8 \%$ had an average knowledge during pretest where as during posttest $71.4 \%$ scored excellent. Also there was a significant increase in the posttest mean score (22.62) compared to the pretest mean (12.67). Similarly the programme was effective in changing the attitude and practice of mothers on prevention of diaper dermatitis.

The study findings are supported by a study conducted by Joseph J E and Mathew S on the effectiveness of Teaching Programme regarding prevention and management of napkin dermatitis in Allahabad. The study comprised of 60 mothers \& the findings showed a less percentage of the pre-test knowledge score $(52.76 \%)$. This shows that there was inadequate knowledge among mothers in all aspects regarding prevention and management of napkin dermatitis in infants and the need for the teaching programme. $^{5}$

Poor adherence with therapy was a major cause of treatment failure in napkin dermatitis as in a study conducted in Department of Dermatology, Ninewells Hospital, Dundee, UK regarding parental knowledge of 
topical therapies in the treatment of childhood napkin dermatitis. The study result showed that the mothers had inadequate knowledge regarding the topical corticosteroid therapy. ${ }^{6}$

\section{Conclusion}

Interventions such as awareness programmes help mothers to gain knowledge on child care. The present study shows that awareness proramme on prevention and management of diaper dermatitis was effective in improving knowledge of mothers. Similarly intervention was effective in changing the attitude and practice of mothers.

\section{References}

1. The bottom line of nappy rash.British Journal of Midwifery .September $2012 ; 20: 9$

2. Hodhod MA, Hamdy AM, Deeb MT, Elmaraghy MO. Cow's Milk Allergy Is a Major Contributor in Recurrent Perianal Dermatitis of Infants.ISRN Pediatr. Sep 3.2012.

3. Scheinfeld N. Diaper dermatitis: a review and brief survey of eruptions of the diaper area.Am J ClinDermatol. 2005; 6(5):273-81.

4. Lavender T, Furber C, Campbell M, Victor S, Roberts I. Effect on skin hydration of using baby wipes to clean the napkin area of newborn babies: assessor-blinded randomised controlled equivalence trial.BMC Pediatr. 2012 Jun 1; 12:59.

5. Joseph J E, Mathew S. The effectiveness of teaching programme regarding prevention and Management of napkin dermatitis. International Journal of Public health science.Vol.2(1)2013

6. LubecG.Treatment of diaper rash with Parfenac lipid ointment (bufexamac), Astudy by Austrian pediatricians,2005(cited 2005 july 14)Available from http://www.ncbi.nlm.gov/pubmed.com 